\title{
PENENTUAN PERBANDINGAN VOLUME FASA MEMBRAN DAN VOLUME FASA INTERNAL SERTA LAMA WAKTU EKSTRAKSI PADA PROSES EKSTRAKSI ION MERKURI MENGGUNAKAN TEKNIK EMULSI MEMBRAN CAIR
}

\author{
Determination of the Ratio of Membrane Phase Volume and Internal Phase Volume and the \\ Extraction Time on the Process of Mercury Ion Extraction using Emulsion Liquid Membrane \\ Technique
}

\author{
* Fulgensia Genefefa T., Baharuddin Hamzah, dan Purnama Ningsih \\ Pendidikan Kimia/FKIP - Universitas Tadulako, Palu - Indonesia 94118 \\ Received 01 June 2017, Revised 03 July 2017, Accepted 01 August 2017
}

\begin{abstract}
This study aimed to determine the optimum condition on the extraction process of mercury ions with the variables of study on the ratio of membrane phase volume and internal phase volume (Mp:Ip) and the extraction time which will provide the greatest percent extraction. Sample used in this study was an artificial sample containing $\mathrm{Hg}(\mathrm{II})$ ions with a concentration of $10 \mathrm{mg} / \mathrm{L}$. $\mathrm{Hg}$ (II) ions will be distributed into internal phase through membrane phase formed from a mixture of surfactants, kerosene and chelating compounds. Concentration of mercury ions remained in the samples was analyzed using a UV-VIS spectrophotometer at a wavelength of $490 \mathrm{~nm}$ with ditizon as a complex. The optimum condition was achieved at a volume ratio of membrane phase (Mp) with internal phase (Ip) of 2:2, and the extraction time was for 10 minutes, where percent extractions were $66.11 \%$ and $82.23 \%$, respectively.
\end{abstract}

Keywords: Mercury ion, membrane phase volume, internal phase volume, extraction time, ditizon

\section{Pendahuluan}

Di era globalisasi ini perkembangan industri sudah semakin pesat. Bahkan keberhasilan pada bidang industri menjadi tolak ukur suatu negara dikategorikan ke dalam negara maju. Perkembangan industri juga telah meningkatkan derajat kehidupan manusia akan tetapi perlu disadari bahwa aktivitas industri dengan segala produknya dapat menimbulkan masalah baru bagi lingkungan baik itu berupa pencemaran udara, darat maupun air. Salah satu pencemaran yang sangat berbahaya yaitu pencemaran yang diakibatkan oleh logam berat seperti merkuri, timbal, mangan, arsen dan kadmium. Logam berat umumnya bersifat racun terhadap makhluk hidup, walaupun beberapa diantaranya diperlukan dalam jumlah kecil. Melalui berbagai perantara, seperti udara, makanan, maupun air yang terkontaminasi oleh logam berat, logam tersebut dapat terdistribusi ke bagian tubuh manusia dan sebagian akan terakumulasikan. Jika keadaan ini berlangsung terus menerus, dalam jangka waktu lama dapat mencapai jumlah yang membahayakan kesehatan manusia (Supriyanto, dkk., 2007)

Salah satu logam berat yang sering kali dijumpai di dalam limbah industri yaitu merkuri $(\mathrm{Hg})$. Unsur merkuri telah diketahui sejak 4000 tahun yang lalu. Merkuri merupakan logam yang berwujud cair pada suhu ruang dan saat ini telah banyak digunakan dalam dunia industri modern (Rimjhim, dkk., 2013). Pada industri pertambangan logam mulia dengan

*Correspondence

Fulgensia Genefefa T

Program Studi Pendidikan Kimia, Fakultas Keguruan dan IImu Pendidikan, Universitas Tadulako

e-mail: fgenefefa@gmail.com

Published by Universitas Tadulako 2017 metoda pengolahan amalgamasi, yakni proses pengikatan logam mulia dari bijihnya menggunakan merkuri dalam tabung amalgamator (Widodo, 2008). Proses pengolahan biji emas yang dilakukan di Kawasan Poboya yaitu proses amalgamasi dimana proses penggilingan dan proses pembentukan amalgam dilaksanakan bersamaan di dalam suatu amalgamator yang disebut tromol (Mirdat, dkk., 2013). Berdasarkan penelitian yang dilakukan oleh Mirdat dkk., (2013) diketahui bahwa konsentrasi merkuri $(\mathrm{Hg})$ dalam tanah berkisar 0,57 ppm-8,19 ppm sedangkan pada limbah berkisar 84,15 ppm sampai $575,16 \mathrm{ppm}$ sehingga dengan demikian dapat disimpulkan bahwa kandungan logam berat merkuri $(\mathrm{Hg})$ dalam tanah di areal kelurahan Poboya sudah melewati ambang yang bisa di toleransi.

Merkuri adalah unsur kimia sangat beracun (toxic), dapat bercampur dengan enzim di dalam tubuh manusia menyebabkan hilangnya kemampuan enzim untuk bertindak sebagai katalisator untuk fungsi tubuh yang penting. Logam $\mathrm{Hg}$ ini dapat terserap ke dalam tubuh melalui saluran pencernaan dan kulit. Karena sifat beracun dan cukup volatil, maka uap merkuri sangat berbahaya jika terhisap, meskipun dalam jumlah yang sangat kecil. Merkuri bersifat racun yang kumulatif, dalam arti sejumlah kecil merkuri yang terserap dalam tubuh dalam jangka waktu lama akan menimbulkan bahaya (Setiabudi, 2005).

Menurut Wurdiyanto (2007) logam merkuri apapun jenisnya sangatlah berbahaya pada manusia karena merkuri akan terakumulasi pada tubuh dan bersifat neurotoxin. Berdasarkan fakta bahaya yang ditimbulkan oleh adanya kandungan merkuri maka perlu dilakukan penanganan terhadap limbah hasil industri untuk meminimalisir terjadinya pencemaran oleh kandungan logam berat seperti merkuri. Salah 
satu cara yang dikembangkan oleh Jasmidi (2001) yaitu dengan menggunakan bantuan mikroorganisme (dalam hal ini Saccharomyces cerevisiae). Adapun cara pengolahan limbah industri yang sedang berkembang sekarang ini yaitu teknik emulsi membran cair.

Proses emulsi membran cair memiliki beberapa keuntungan antara lain, proses pemisahan yang sederhana, efisiensi tinggi serta proses ekstraksi dan re-ekstraksi berlangsung dalam satu wadah. Emulsi membran cair memiliki selektivitas tinggi dalam pemisahan ion logam dengan konsentrasi rendah dan hanya membutuhkan sedikit pelarut organik (Mohamed, dkk., 2013). Membran cair emulsi dibuat dengan membentuk emulsi dari dua fasa cair yang tidak saling campur dan kemudian emulsi yang terbentuk didispersikan ke fasa eksternal. Fasa eksternal mengandung spesies yang akan dipisahkan sedangkan fasa internal merupakan fasa penerima spesies yang telah dipisahkan setelah melewati membran cair (Bartsch \& Way, 1996). Untuk menstabilkan emulsi, selarna proses ekstraksi ditarnbahkan surfaktan yang berfungsi untuk menurunkan tegangan pada bidang antarrnuka dari setiap fasa (Prayitno, dkk., 2000). Surfaktan bekerja dengan membentuk film yang teradsorpsi pada antarmuka butiran terdispersi dan medium pendispersi. Bagian polar surfaktan berada dalam air sedangkan bagian nonpolarnya berada dalam minyak sehingga film yang teradsorpsi akan menurunkan tegangan antarmuka sampai bernilai nol sehingga pengemulsian akan terjadi secara spontan dan dengan sendirinya akan mengurangi jumlah harga mekanik yang diperlukan untuk memecah fasa dalam menjadi butiran-butiran terdispersi (Castellan, 1983).

Skema mekanisme reaksi dalam proses emulsi membran cair ditunjukkan pada Gambar 1.

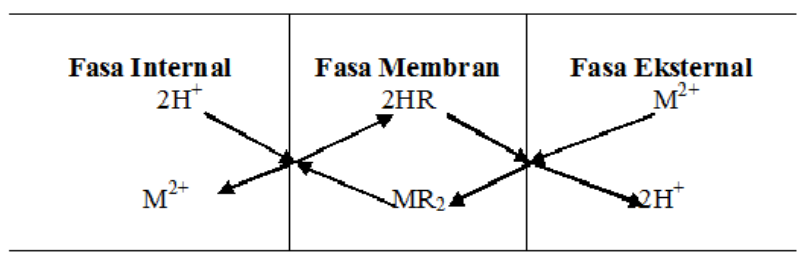

Gambar 1. Mekanisme reaksi kimia dalam membran cair

Mekanisme yang terlihat pada Gambar 1 umumnya digunakan untuk pemisahan ion logam dan didasarkan pada reaksi yang terjadi antara ion logam misalnya $\mathrm{M}^{2+}$ dengan pereaksi $\mathrm{HR}$ (zat pembawa) yang dilarutkan dalam membran. Adanya pengadukan menyebabkan terjadinya reaksi pada permukaan luar membran antara $\mathrm{M}^{2+}$ dengan zat pembawa, membentuk kompleks $\mathrm{MR}_{2}$ yang larut baik dalam membran. Kemudian kompleks ini berdifusi di dalam membran cair menuju fasa internal. Oleh karena adanya zat pembebas di dalam fasa internal, maka $\mathrm{M}^{2+}$ akan dilepaskan dari senyawa kompleksnya pada permukaan dalam membran; selanjutnya zat pembawa HR yang telah melepaskan $\mathrm{M}^{2+}$ tersebut akan berdifusi kembali ke permukaan luar membran untuk membentuk kompleks yang baru dengan $\mathrm{M}^{2+}$ lainnya. Akibatnya, konsentrasi kompleks pada permukaan dalam fasa membran menjadi sangat kecil sehingga menyebabkan terjadinya gradien konsentrasi kompleks pada permukaan luar dan permukaan dalam (Hamzah, dkk., 2011).

Proses ekstraksi dengan menggunakan teknik emulsi membran cair dipengaruhi oleh banyak variabel diantaranya: pengaruh perbandingan volume fasa membran dan volume fasa internal; pengaruh lama waktu ekstraksi; pengaruh konsentrasi surfaktan; pengaruh perbandingan volume emulsi dan volume fasa eksternal; pengaruh konsentrasi pengkhelat (misalkan benzoil aseton); pengaruh $\mathrm{pH}$ fasa eksternal; pengaruh konsentrasi asam dalam fasa internal serta pengaruh konsentrasi ion logam (Prayitno, dkk., 2000).

Tulisan ini dimaksudkan untuk memberikan informasi mengenai kondisi optimum dengan variabel penelitian berupa perbandingan volume fasa membran dan volume fasa internal serta lama waktu ekstraksi pada proses ekstraksi ion merkuri yang nantinya akan memberikan persen ekstraksi terbesar.

\section{Metode}

Alat

Alat yang digunakan berupa spektrofotometer UV-VIS Perkin Elmer Lamda 25, kuvet, gelas kimia, labu ukur, pipet volume, karet penghisap, neraca digital $A N D G R-200$, pipet tetes, corong pisah, statif dan klem, spatula, batang pengaduk, gelas ukur, wadah plastik, $\mathrm{pH}$ meter Lamotte, Cimarec Stirring and Hot Plate Cole Parmer dan magnetic stirrer.

\section{Bahan}

Bahan-bahan yang digunakan pada penelitian ini meliputi: kristal $\mathrm{HgCl}_{2}$ (E. Merck), benzoil aseton (Merck Schuchardt OHG), span 20 (Merck Schuchardt $O H G$ ), span 80 (Merck Schuchardt OHG), kerosen, aquades, asam klorida $(M e r c k)$, ditizone dalam $\mathrm{CCl}_{4}$.

\section{Pengaruh perbandingan volume fasa membran dan volume fasa internal terhadap persen ekstraksi ion merkuri}

$30 \mathrm{~mL}$ emulsi ditambahkan ke dalam $210 \mathrm{~mL}$ larutan merkuri $10 \mathrm{ppm}$ dengan $\mathrm{pH}$ 3. Emulsi dibuat melalui pencampuran fasa membran (yang mengandung 0,015 $\mathrm{M}$ benzoil aseton dan 4\% surfaktan campuran) dan fasa internal dengan perbandingan volume $2: 1 ; 2: 2 ; 2: 3$; dan $2: 4$ dengan kecepatan emulsifikasi pada skala 10 selama 10 menit. Proses ekstraksi dilakukan dengan kecepatan pengadukan pada skala 1,5 selama 15 menit. Setelah ekstraksi, fasa eksternal dipisahkan dari emulsi dengan menggunakan corong pisah kemudian diukur konsentrasi ion merkuri dengan spektrofotometer UV-VIS. Perbandingan volume fasa membran dan fasa internal yang akan digunakan untuk percobaan selanjutnya adalah perbandingan volume yang memberikan persen ekstraksi terbesar (Alam, 2014). 
Pengarub lama waktu ekstraksi terhadap persen ekstraksi ion merkuri

Proses ekstraksi dilakukan sama seperti perlakuan sebelumnya, hanya saja mengganti perbandingan volume fasa membran dengan fasa internal dengan hasil yang diperoleh pada percobaan sebelumnya yang memberikan persen ekstraksi terbesar yakni pada perbandingan 2:2. Selain itu, pada perlakuan ini lama waktu ekstraksi divariasikan yakni 5 menit; 10 menit; 15 menit dan 20 menit (Alam, 2014).

\section{Analisis kandungan merkuri yang tersisa pada fasa eksternal}

Sampel hasil ekstraksi masing-masing diencerkan dengan aquades hingga pengenceran $10 \mathrm{kali}$. Sampel hasil pengenceran kemudian ditambahkan larutan ditizone $0,001 \%$ dalam $\mathrm{CCl}_{4}$ sebanyak $5 \mathrm{~mL}$ (suasana asam) secara perlahan sambil mengaduknya hingga diperoleh warna yang stabil. Larutan yang terbentuk terdiri dari dua lapisan sehingga perlu dipisahkan dengan corong pisah. Fasa yang dianalisis merupakan fasa organik yang berwarna orange. Larutan standar yang digunakan yaitu larutan $\mathrm{Hg}$ (II) dengan konsentrasi 0,$15 ; 0,25 ; 0,35$ dan $0,5 \mathrm{ppm}$. Penentuan konsentrasi sampel didasarkan pada persamaan regresi deret standar dengan menggunakan instrumen spektrofotometer $U V$-VIS pada panjang gelombang $490 \mathrm{~nm}$ (Cahayani, 2014).

\section{Hasil dan Pembahasan}

\section{Pengukuran absorbansi larutan standar}

Larutan yang digunakan dalam analisis secara spektrofotometer UV-VIS harus memenuhi syarat untuk absorpsi sinar tampak yakni larutan harus berwarna. Larutan cuplikan yang tidak berwarna dibuat berwarna dengan suatu pereaksi yang dapat menghasilkan warna (Kristianingrum, 2010). Hal yang sama dilakukan pula pada analisis $\mathrm{Hg}(\mathrm{II})$ dimana zat pengompleks yang digunakan yaitu larutan ditizon dalam $\mathrm{CCl}_{4}$.

Reaksi antara ion $\mathrm{Hg}^{2+}$ dengan pereaksi ditizon ( $\mathrm{HDz}$ ), ditunjukkan dalam persamaan:

$\mathrm{Hg}^{2+}+2 \mathrm{H}_{2} \mathrm{Dz}\left(\mathrm{fo}_{0} \leftrightarrow \mathrm{Hg}(\mathrm{HDz})_{2}+2 \mathrm{H}^{+}{ }_{(\mathrm{a})}\right.$

Ion logam $\mathrm{Hg}$ (II) dapat bereaksi dengan ditizon membentuk senyawa kompleks merkuri ditizonat berwarna orange yang dapat dianalisis secara spektrofotometri $U V$-Visible. Struktur senyawa merkuri ditizonat ditunjukkan pada Gambar 2.

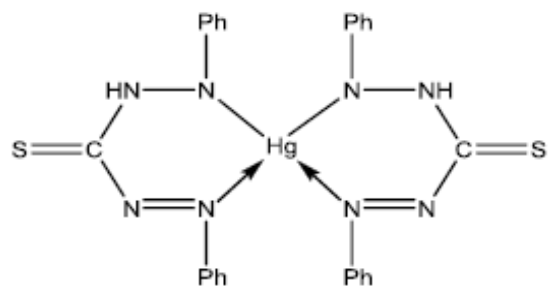

Gambar 2. Struktur senyawa kompleks merkuri ditizonat

Larutan kompleks yang diperoleh selanjutnya dianalisis menggunakan instrumen spektrofotometer
UV-VIS pada panjang gelombang $490 \mathrm{~nm}$ (Prastiva, 2014). Penentuan konsentrasi sampel nantinya akan didasarkan pada persamaan regresi dari deret absorbansi larutan standar. Berdasarkan data hasil pengukuran maka diperoleh grafik persamaan regresi linear yang menunjukkan hubungan konsentrasi larutan standar merkuri seperti yang ditunjukkan pada Gambar 3.

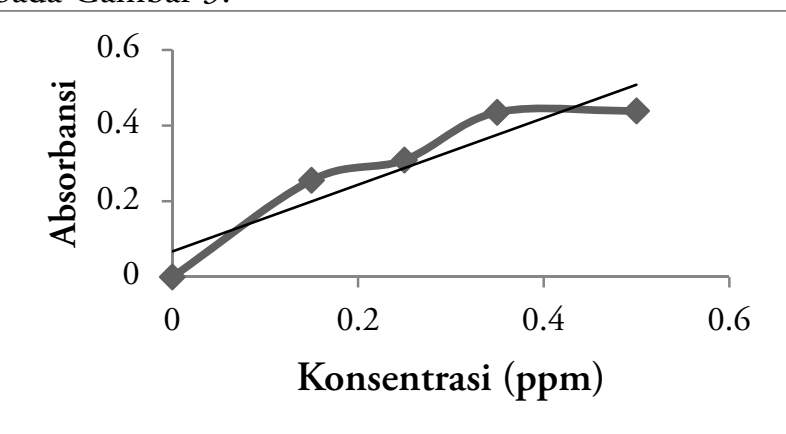

Gambar 3. Hubungan Konsentrasi larutan standar $\mathrm{Hg}(\mathrm{II})$ dengan absorbansi

Data yang ditunjukkan pada Gambar 3 menjelaskan bahwa adanya hubungan linearitas antara konsentrasi dan absorbansi. Nilai koefisien korelasi yang diperoleh yaitu 0,877 dimana nilai koefisien korelasi yang mendekati 1 menunjukkan adanya hubungan yang linear antara absorbansi yang terukur dengan konsentrasi.

\section{Pengaruh perbandingan volume fasa membran dan volume fasa internal terhadap persen ekstraksi ion merkuri}

Sampel yang dibuat dengan menvariasikan volume fasa membran dan volume fasa internal selanjutnya diencerkan dengan menggunakan aquades. Hasil pengenceran kemudian dikomplekskan dan diukur absorbansinya menggunakan alat spektrofotometer $U V$-VIS pada panjang gelombang $490 \mathrm{~nm}$. Data absorbansi yang diperoleh akan digunakan untuk menentukan konsentrasi sampel dan besarnya persen ekstraksi. Berdasarkan hasil analisis dan pengolahan data maka diperoleh data seperti yang terlihat pada Gambar 4 tentang pengaruh perbandingan volume fasa membran dan fasa internal terhadap persen ekstraksi ion merkuri.

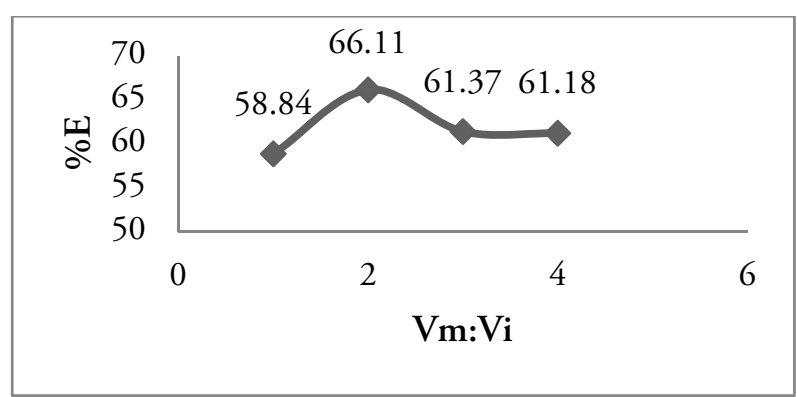

Gambar 4. Grafik pengaruh Vm:Vi terhadap persen ekstraksi ion merkuri

Keterangan perbandingan

$\mathrm{Vm}: \mathrm{Vi}: 1=2: 1 ; 2=2: 2 ; 3=2: 3 ; 4=2: 4$ 
Berdasarkan grafik yang ditunjukkan pada Gambar 4 terlihat bahwa perbandingan Vm:Vi yang memberikan persen ekstraksi terbesar yaitu 2:2. Hal ini disebabkan karena pada perbandingan tersebut terjadi keseimbangan antara jumlah volume fasa membran dan fasa internal sehingga emulsi yang terbentuk relatif lebih stabil dibandingkan pada perbandingan lainnya (Hamzah, dkk., 2011). Perbandingan 2:1 ( $\mathrm{Vm}: \mathrm{Vi})$ terlihat menghasilkan persen ekstraksi yang lebih kecil. Hal ini diakibatkan oleh volume fasa membran yang lebih besar dari volume fasa internal, artinya konsentrasi surfaktan menjadi besar di fasa membran dan berdampak pada lebih rapatnya surfaktan pada fasa membran sehingga dapat menghalangi transpor ion logam yang akan dipisahkan (Santoso, dkk., 2007).

Pada perbandingan kedua terakhir yakni 2:3 dan 2:4 terlihat memberikan persen ekstraksi yang cukup besar akan tetapi belum maksimal dikarenakan pada perbandingan ini volume fasa internal lebih besar maka secara keseluruhan fasa internal tidak dapat terlapisi oleh fasa membran. Hal ini menyebabkan fasa membran yang melapisi fasa internal menjadi tipis akibatnya emulsi mudah pecah dan merkuri yang telah masuk ke fasa internal akan kembali ke fasa eksternal (Santoso, dkk., 2007).

\section{Pengaruh lama waktu ekstraksi terhadap persen ekstraksi ion merkuri}

Kondisi optimum pada variabel sebelumnya yang memberikan persen ekstraksi terbesar diperoleh pada perbandingan 2 : 2 (Vm:Vi). Perbandingan ini selanjutnya digunakan pada pembuatan emulsi untuk melihat pengaruh lama waktu ekstraksi. Variasi waktu ekstraksi yang digunakan yaitu 5 menit, 10 menit, 15 menit dan 20 menit. Sampel hasil ekstraksi selanjutnya diencerkan dengan aquades dan dikomplekskan sehingga dapat diukur absorbansinya. Data absorbansi yang diperoleh akan digunakan untuk menentukan konsentrasi sampel serta persen ekstraksi. Berdasarkan hasil olahan data maka diperoleh data persen ekstraksi ion merkuri dengan variabel pengamatan pengaruh waktu ekstraksi terhadap persen ekstraksi seperti yang terlihat pada Gambar 5.

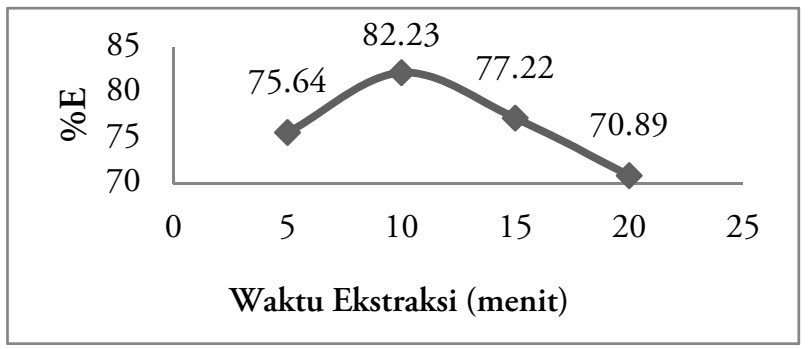

Gambar 5. Grafik pengaruh waktu ekstraksi terhadap persen ekstraksi $\mathrm{Hg}$ (II)

Berdasarkan data yang ditunjukkan pada Gambar 5 terlihat bahwa pada waktu ekstraksi 5 menit belum mencapai keadaan optimal dikarenakan waktu yang relatif singkat sehingga belum seluruhnya merkuri yang terekstraksi ke dalam emulsi. Kondisi optimal diperoleh pada waktu ekstraksi 10 menit dimana menghasilkan persen ekstraksi sebesar 82,23\%. Menurut data hasil penelitian dengan waktu ekstraksi yang lebih lama dari 10 menit terjadi penurunan persen ekstraksi. Hal ini dapat dijelaskan dengan teori bahwa dengan semakin lamanya waktu ekstraksi maka daya pisah membran emulsi cair mulai berkurang. Hal ini disebabkan karena terjadinya osmosis sehingga membran emulsi pecah. Terjadinya osmosis menyebabkan membran menjadi tipis dan kemudian pecah (Prayitno, dkk., 2000). Akibat dari menipisnya membran dapat berdampak pada ion $\mathrm{Hg}$ (II) yang telah berada dalam fasa membran akan kembali ke fasa eksternal (Sanjaya, 2011).

\section{Kesimpulan}

Kondisi optimum dengan variabel penelitian berupa perbandingan volume fasa membran dan fasa internal yang memberikan persen ekstraksi terbesar pada proses ekstraksi ion merkuri dengan teknik emulsi membran cair diperoleh pada perbandingan 2:2 dengan persen ekstraksi (\%E) sebesar $66,11 \%$ serta variabel waktu ekstraksi yang juga memberikan persen ekstraksi terbesar yaitu pada waktu 10 menit dengan persen ekstraksi sebesar 82,23\%.

\section{Ucapan Terima Kasih}

Ucapan terima kasih penulis sampaikan pihak Laboratorium Kimia FKIP Universitas Tadulako, dalam hal ini kepada Tasrik, Husnia dan Nurbaya selaku laboran di Laboratorium Kimia FKIP Universitas Tadulako.

\section{Referensi}

Alam, S. (2014). Penentuan kondisi optimum ekstraksi ion timbal (II) menggunakan teknik emulsi membran cair. Palu: Universitas Tadulako.

Bartsch, R. A., \& Way, J. D. (1996). Chemical separations with liquid membranes. ACS Symposium Series, 642, 1-2.

Cahayani, A. D. (2014). Pengujian metode spektrofotometri uv-vis untuk penentuan $H g(I I)$ dalam limbah cair laboratorium FMIPA UGM dengan pereaksi ditizon. Yogyakarta: Universitas Gadjah Mada.

Castellan, G. (1983). Physical chemistry (3rd ed.). California: The Benjamin/ Cummings Publishing Co. Inc.

Hamzah, B., Jalaluddin, N., Wahab, A. W., \& Upe, A. (2011). Pengaruh ion kadmium(II) dan nikel(II) pada ekstraksi ion tembaga(II) dengan ekstraktan 4-benzoil-1-fenil-3-metil-2-pirazolin5-on menggunakan emulsi membran cair. Jurnal Natur Indonesia, 13(3), 269-275.

Herman, D. Z. (2006). Tinjauan terhadap tailing mengandung unsur pencemar arsen (As), merkuri $(\mathrm{Hg})$, timbal $(\mathrm{Pb})$ dan cadmium $(\mathrm{Cd})$ dari sisa pengolahan bijih logam. Jurnal Geologi Indonesia, 1(1), 31-36. 
Jasmidi. (2001). Pengaruh pH awal larutan terhadap biosorpsi mangan(II) oleh biomassa Sacchromyces cerevisiae. Jurnal Pendidikan Sains, 25(3), 11-19.

Kristianingrum, S. (2010). Handout spektroskopi ultra violet dan sinar tampak (spktroskopi uv-vis). from staff.uny.ac.id/sites/default/files/pendidikan/Susi la Kristianingrum, Dra., M.Si./ Handoutinstrumen-UV-vis-Susi.pdf

Mirdat, Pata'dungan, Y. S., \& Isrun. (2013). Status logam berat merkuri $(\mathrm{Hg})$ dalam tanah pada kawasan pengolahan tambang emas di kelurahan Poboya, kota Palu. e-J. Agrotekbis, 1(2), 127134.

Mohamed, Y. T., Hussin, L. M. S., Gad, H. M. H., Daifullah, A. A. M., \& Abo-El-Enein, S. A. (2013). Membrane stability and removal of cobalt from waste solution using liquid emulsion membrane. Journal of Membrane and Separation Technology, 2(1), 102-108.

Prastiva, A. (2014). Analisis ion Hg(II) dalam krim pemutih secara spektrofotometri uv-vis. Yogyakarta: Universitas Gadjah Mada.

Prayitno, Sardjono, D., \& Hakim, L. (2000). Penurunan kadar merkuri pada limbah cair dengan teknik membran emulsi cair. Paper presented at the Presentasi Ilmiah Keselamatan Radiasi dan Lingkungan VIII.

Rimjhim, J., Kumar, S. S., Uma, A., Saurabh, K., \& Neha, S. (2013). Mercury toxicity and its management. International Research Journal of Pharmacy, 4(8), 38-41.

Sanjaya, R. (2011). Ekstraksi ion Cd(II) menggunakan membran cair emulsi bersurfaktan span-80 dengan ekstraktan 1-fenil-3-metil-4-benzoil-5-pirazolon. Makassar: Universitas Hasanuddin.

Santoso, I., Buchari, Amran, M. B., \& Sulaeman, A. (2007). Ekstraksi dan pemisahan penisilin G dari fenilasetat dengan teknik membran cair emulsi. Jurnal Matematika dan Sains, 12(3), 94101 .

Setiabudi, B. T. (2005). Penyebaran merkuri akibat usaha pertambangan emas di daerah Sangon, Kabupaten Kulon Progo, D.I Yogyakarta. Kolokium Hasil Lapangan (61), 1-17.

Supriyanto, Samin, \& Kamal, Z. (2007). Analisis cemaran logam berat $\mathrm{Pb}, \mathrm{Cu}$, dan Cd pada ikan air tawar dengan metode spektrometri nyala serapan atom (SSA). Paper presented at the Seminar Nasional III SDM Teknologi Nuklir Yogyakarta.

Widodo. (2008). Pengaruh perlakuan amalgamasi terhadap tingkat perolehan emas dan kehilangan merkuri. Jurnal Riset Geologi dan Pertambangan, 18(1), 47-53.

Wurdiyanto, G. (2007). Merkuri, bahayanya dan pengukurannya. Buletin Alara, 9(1,2). 